Journal of Social Sciences (COES\&RJ-JSS)

ISSN (E): 2305-9249 ISSN (P): 2305-9494

Publisher: Centre of Excellence for Scientific \& Research Journalism, COES\&RJ LLC

Online Publication Date: 1st July 2016

Online Issue: Volume 5, Number 3, July 2016

http://centreofexcellence.net/J/JSS/JSS\%20Mainpage.htm

\title{
The concept of freedom and progress in Arab Renaissance thought Saqer Ali Moham'd
}

\begin{abstract}
:
This study aimed to analyze the basis of the intellectual and historical concepts that governed the orientations of the pioneers of Arab Renaissance thought in their application of freedom and progress ideas, which represent the most important issues of the Renaissance thought. It is also aimed to highlight some of the efforts and attempts of the Renaissance generation in the search for consensual form that get these two concepts (freedom, progress)closer, while trying to integrate them within the Arab society's way of life.

The study concluded that the search in both concepts had formed other concepts to rise, in regards to democratic state and human rights, whether they are derived from the Arab Islamic heritage or from the Western civilization thoughts and believes.
\end{abstract}

Keywords:

Freedom, progress, Arab renaissance

\section{Citation:}

Moham'd, Saqer Ali (2016), The concept of freedom and progress in Arab Renaissance thought; Journal of Social Sciences (COES\&RJ-JSS), Vol.5, No.3, pp: 444-458. 


\section{مفهوم الحرية والتقدم في الفكر النهضوي العربي

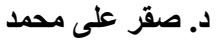

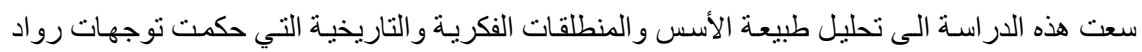

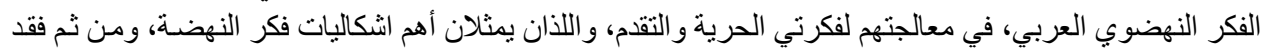

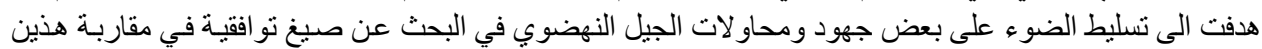

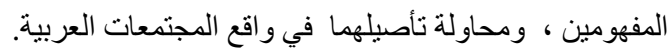
وخلصت هذه الدر اسة إلى أن كلا من المفهومين من قبيل الديل الدولة الديمقر اطية وحقوق الانسـان، (الحريـة و التقدم) قد بلور ا مفاهيم أخرى سواء أكانت مستقاه من داخل التراث العربي الإسـلامي أم من داخل فكر الحداثة الأنة الغربي الو افد.

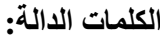
الحرية ، التقدم، النهضة العةد العربية.

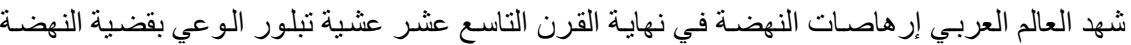

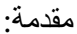

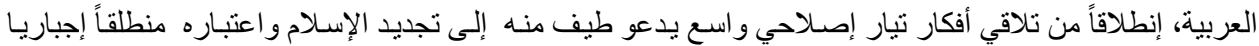

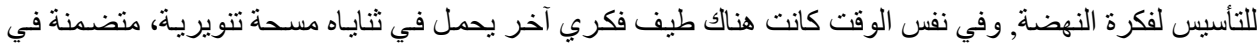

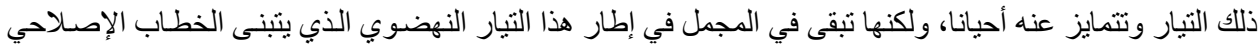

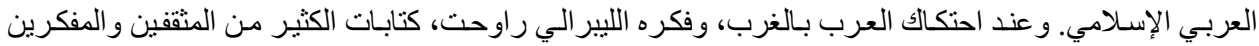

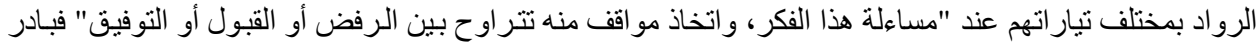

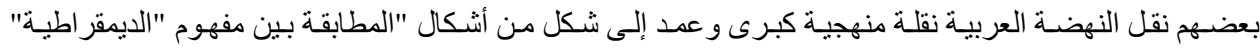

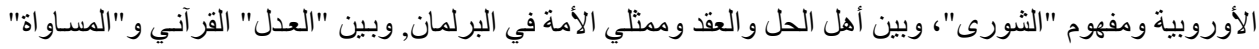

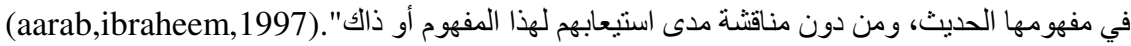
لقد أوضح حسن حنفي بأن فجر النهضة العربية بدأ منذ قرنين من الزمان بثناثلة بدايات متمايزة بعتبرها جادة و أصبله.. (hanfie,Hasan,2001) الأولى: الدين الإسلامي، فالأفغاني (1838-1897م) بر أيسه وضـع أسس الأيديولوجيـة الإسـامية الثوريـة،

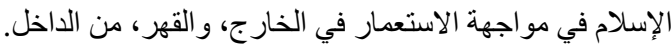

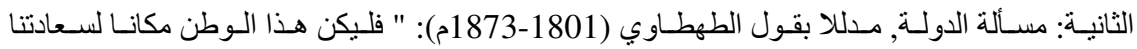

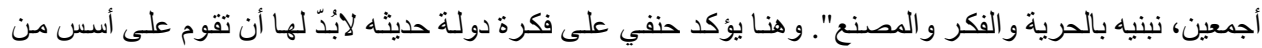

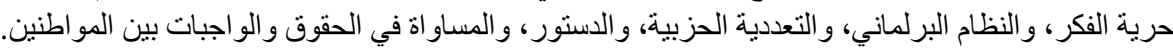

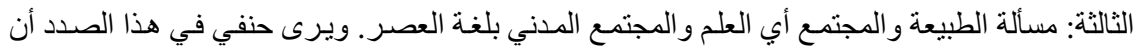

شبلي شميل (1850-1917) أسس التيار العلماني، وفتح رافداً جديداً في التقافة العربية، ومواجهة القدئية القديم بالحديث.

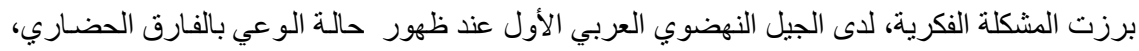

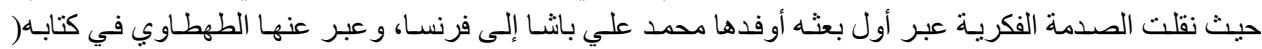

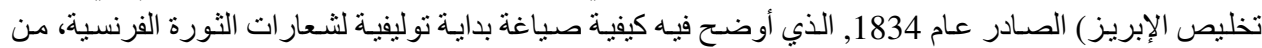

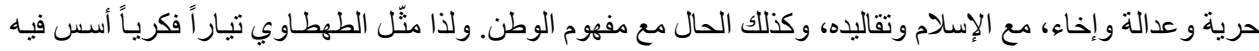

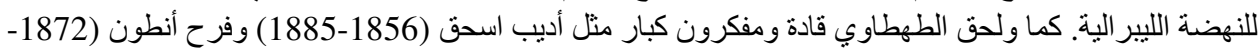

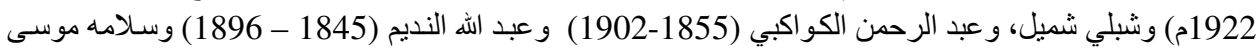
(1887-1958م)، كما تأثر مفكرون إسلاميون بأفكاره، و أفكار الثورة الفرنسية، أمثال الأفغاني ومحمد عبده (1849) (1849)

(khurie,raef,1943). (1905 
إثكالية الاصالة والمعاصرة في الفكر العربي الحديث:

برزت فكرة الإصـلاح في الفكر العربي الإسـلامي في أواخر القرن التاسـع عشر بوصفه المـرادف لعملية التحديث، أي نقل التكنولوجيا والعلوم الغربية إلى المجتمعات العربية والإسـلامية. وظهر أن دعاة الفكر الإصـلاحي في القرن التاسع عشر كانوا يؤمنون إيمانًا كبيراً بأن عملية النقل هذه يمكن انجازها بإثراف القوى الطبقية المسيطرة

نفسها. ،. (Daheer,Masoud,1980) بيد أن الفكر الإصلاحي لهذه المرحلة كان عاجزاً عن التصدي للخطر الاستعماري الأوروبي ولذا فقد ارتكز هذا الفكر إلى التخفيف "من مساوئ الاستبداد والفردية التي تميز بها ممتلو القوى الطبقية المسيطرة، وتقليص هيمنة الإنة

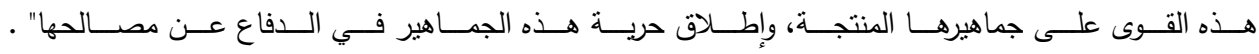
(daheer,masud,1980). وذلك من أجل المساهمة في الكثف عن الجوانب الإنسانية في الممارسات الاجنماعية والاقتصادية ومحاولة رسم صورة جديدة للمستقبل. من الممكن النظر إلى الأفكار الإصـاحية، في الفكر العربي في عصدر النهضئهة بوصفها عملية تغيير

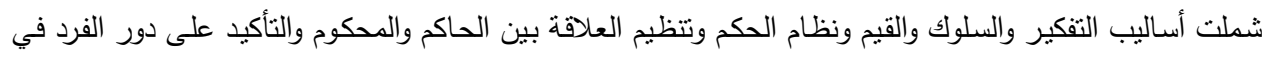

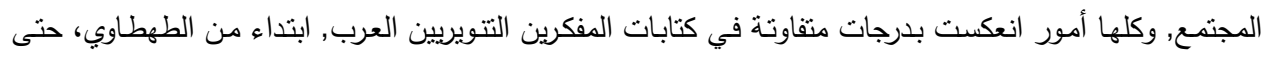
محمد عبده والكواكبي وفرح أنطون وأديب إسحق وغيرهم، ما يعني أن التتوير لم يكن مجرد عملية تغيّر نقافي أو أن

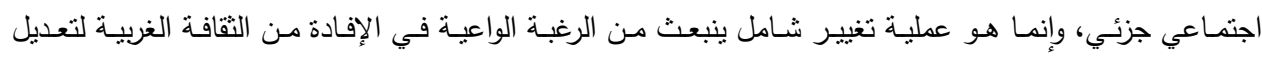
الأوضاع القائمة, والخروج من حاله التخلف والركود التي سبطرت على الفكر العربي والمجتمعات العربية، واللحاق التهن بالعالم الغربي لتحقيق النمـوذج/ الحم المثالي الذي ينبغي الاقتداء بـه في حدود معينة تأخذ في الاعتبار الثقافة

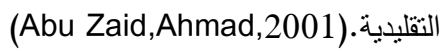
بات الغرب بوصفه من زاويـة ما مثال التقدم، يشكل في بعض نيارات الوعي العربي أنموذجاً ومعياراً ولّد شعوراً حاداً، بالتأخر والانكسار , فقد أحب العرب الغرب وكرهوه في الوقت نفسه، وذللك بقدر حبهم لذاتهم وتعلقهم

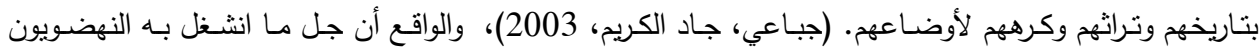
العلمانيون، والإصلاحيون الإسلاميون، والقوميون الليبراليون، والتقدميون، منذ قرن ونيّف قد تمثل في إثنالية السلطة وتداول شأنها من أجل تسهيل مسار التقدم والتفاعل الحضاري مع الآخر ..(mursho,gregwar,1999)

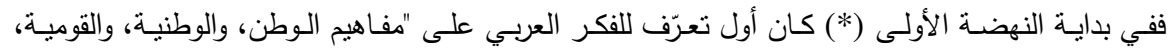

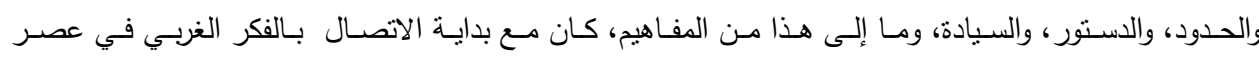
(النهضة".) (saed,saed bn ,1986)

خلّّت الحملة الفرنسية على مصر ، تأثثراً لافتاً على الفكر العربي، عموماً في محاولات عَدة منها: صعود

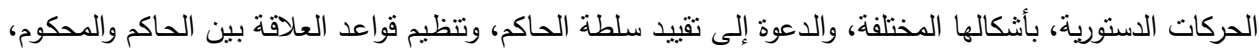

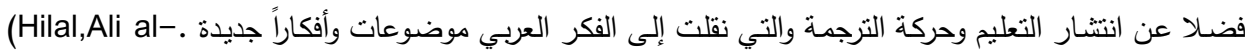

(*) وهي المرحلة التاريخية التي اجتازها العرب من حملة نابليون على مصر حتى نهاية الحرب العالمية الثانية،

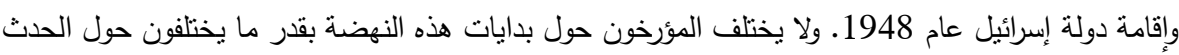

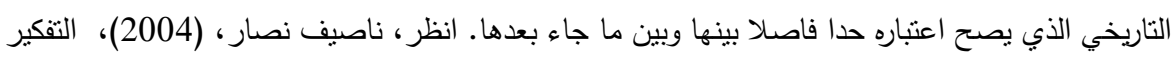

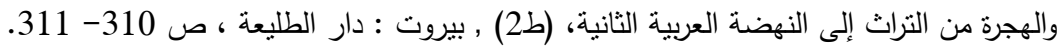


لاقت مبادئ الثنورة الفرنسية (حرية، إخاء، مساواة) التي دخلت عبر مختلف القنوات الاجتماعية والسياسية

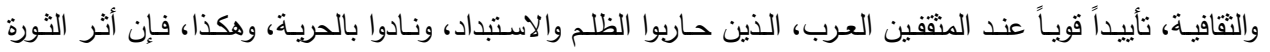

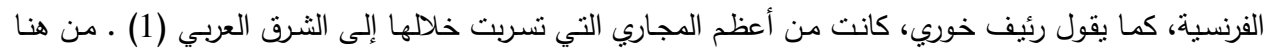

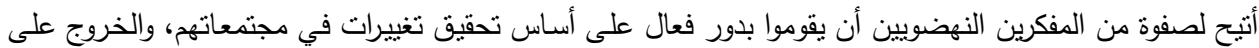

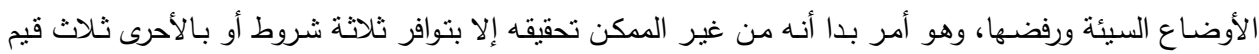

إنسانية عليا هي قيم الحرية والعدالة والعقلانية (abu zaid,ahmad,2001). كما أدرك المثقفون العرب أهمية النهضة الثقافية "لتنارك تخلفهم الحضاري، وشعروا بأن زمام المبادرة لديهم في المجال الثقافي أوسع مما هي في الجالين الاقتصادي والسياسي"... (nassar,Naseef,2004)

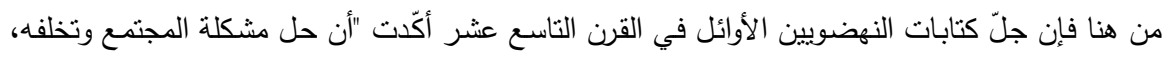
وصورة السلطة فيه، ونمو اقتصاده منوطة بإصلاح التربية" . (al-gmale,hafid,1989)

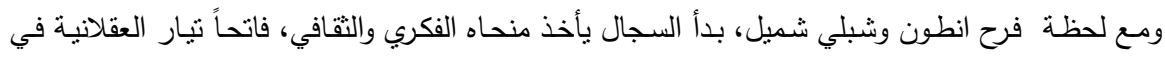

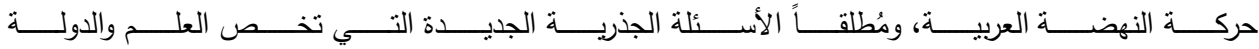
والمجتمع... (giead,hisham,1986)

جاءت فكرة النتوير في الفكر النهضوي العربي بوصفها حصيله للاحتكاك الثقافي لأجل الخروج من العزلة

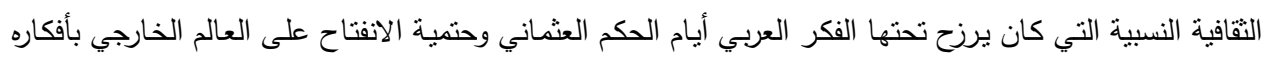

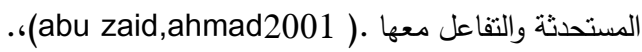

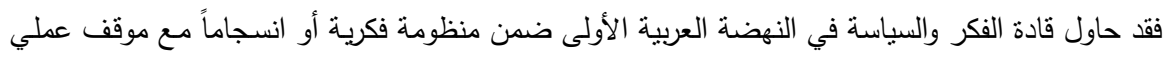

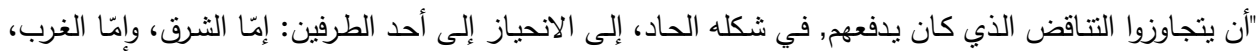

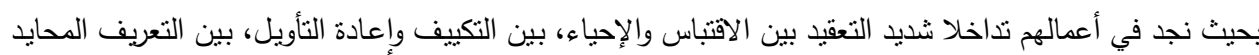

والالتزام الثخصي". ، (Nassar,Naseef,2000) أمـا التصورات التي تطلبها الإصـاح، وكما يتصورها الخطاب الإصـاحي العربي الإسـلامي، على وجـه التحديد, فقد حدّدها (awmlel,Ali,1985)، في كتابه (الإصلاحية العربية) بتصورين:

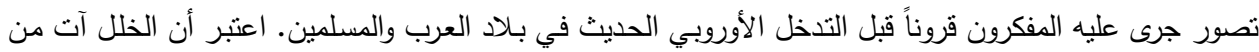
الدجمع الإسلامي نفسه حيث تنفاقم الهوة بينه وبين الإسلام المعياري، أي ما ينبني أن يكون عليه المجتمع إسلاميا.

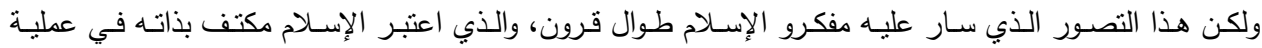

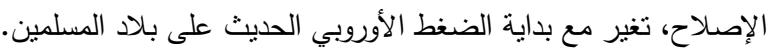
وتصور ثانٍ يرى أن منطق الإصلاح الإنسلامي قد تغير عن القديم في مسألة أساسية: وهي أنه اتجه إلى الغير في الإني تصوره لعملية الإصلاح.

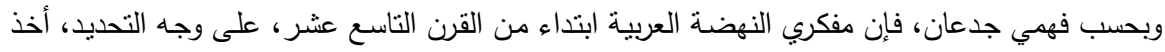
ينشكّل لايهم وعي خاص بإككانية التوفيق أو التركيب بين "النتراث الحي" المنتقي من الحضارة العربية الإسلامية،

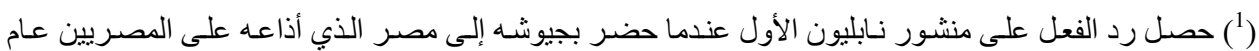

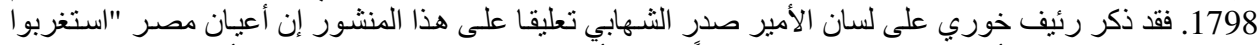

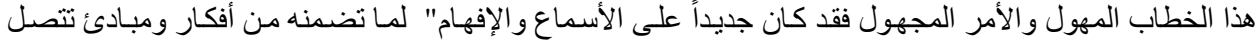

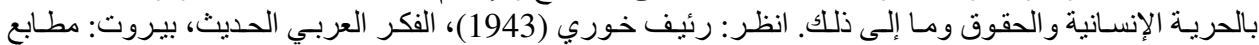




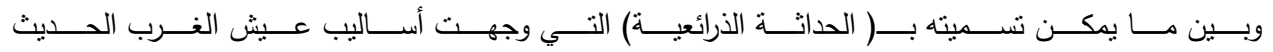

وطرائقه.)(Gdaan,Fahmie, 1996)

إن مشتركات قيم النهضة، عند المفكرين العرب، تمحورت حول أربع أفكار تم تداولها بأنشكال مختلفة طوال

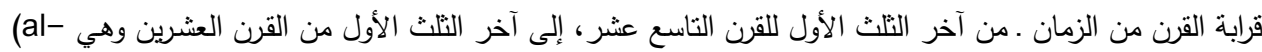

: saed-rdwan,1998)

إن علاقة أوروبا بالمسلمين قائمة على الغلبة، وعلّة هذه الغلبة التقدم الأوروبي، وتخلف المسلمبن.

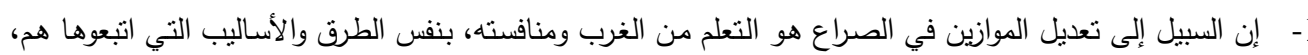

إذ لا مفهوم للتقدم غير ما سنّه أولئك الأوروبيون.

2- أنه لا تتاقض بين الإسلام والتقام، بل إن ذللك هو مقتضى الإسلام، والمقصد العام لثريعته.

أ- النهضة العربية وأطاريحها: التقدم والحرية.

من الواضـح أن فكر النهضة العربية كان قائماً على بنية مجتمع عربي كان قد أخذان، للتوّ، بتجزأ ويتفكّك،

وذلك بعد بدء الإرهاصـات الأولى لسقوط "الدولة العثمانية، وتحول فكر النهضة إلى فكر استقلالي كفاحي، وحتى لهى

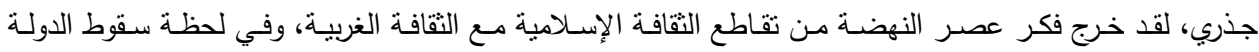

الإسلامية الجامعة، فتحولت العلاقة مع الغرب إلى سؤال حول عوامل السقوط"...(Al-musale,Ahmad,2001)

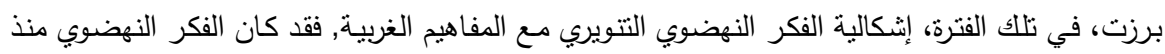
رفاعه الطهطاوي، وحتى جيل ما بين الحربين، فكراً نقدياً مشبعاً بروحٍ نضالية، بنعامل مع حداثة الغرب، من منظور

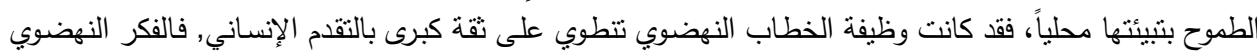

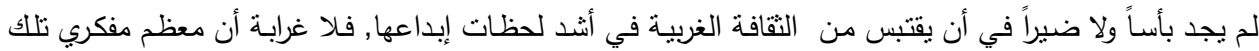

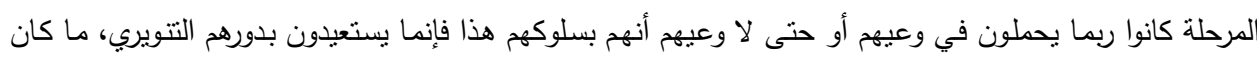

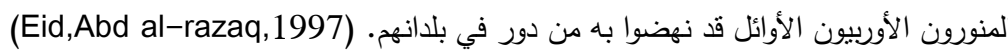

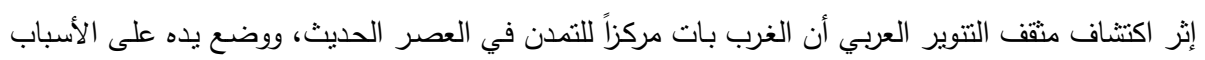
التي ضمنت للأوروبين تقدمه، وجد أن عليه أن يسوّغ عملية اقتباس هذه الاسباب بما يضمن نقل مجتمعه من حالة

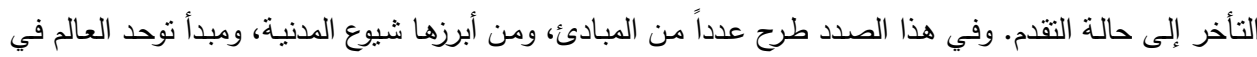

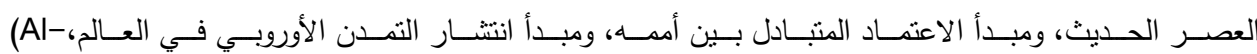
shreef,Maher,2000)

سبق لرواد الإصلاح العربي أن قصدوا أوروبا للكثف عن سر تقدمها، ونهوضها، والتدبر في أمر ما يمكن

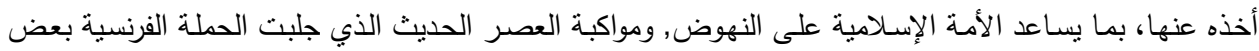

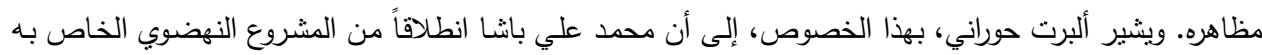
"كان ذا نظرة خاصـة إلى أوروبا الحديثة، كمجتمع نشيط، بينتشر موارده ويدير شؤونه استتاداً إلى العقل، ويتخذ له له

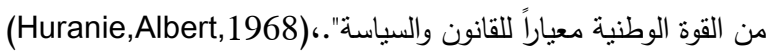
بيد أن حضور فكرة التتوير في فكر رواد النهضة العربية لا يعني أبداً أن جهود هؤلاء المفكرين كانت مجرد محاكاة، ومماتلة لفكر التتوير , بقدر بينّت رغبة هذه النخبة في إيجاد مرجعية مقارنة لتسمح لهم بنتريع ما كانوا يرونه لهنه 
ضرورياً ألا وهو أعادة قراءة الدين قراءة تحررية، ليكون باعثا أساسيا على هذا التطوير وعلى هذا الاجتهاد..-bl) rashed,mohammad,2009)

إن إنكالية النهضة والنهضويين تمخضت عن ازدواجية في النظر، لكن النموذج، وهو الغرب، بنظرهم "كان

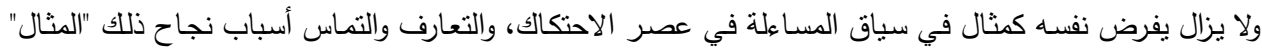
على مستوى "الداخل" قبل مستوى علاقة دولته وسياستها بخارجه".. (kawthraie,wageh,2002)

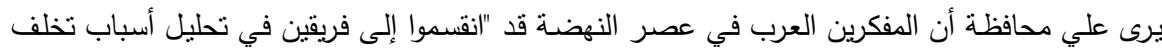
أمنهم: فريق السلفيين الذين أرجعوا هذا التخلف إلى ابتعاد المسلمين عن الدين القويم، وفريق الليبراليين الذين حاولوا

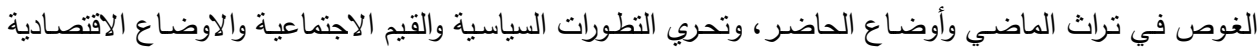

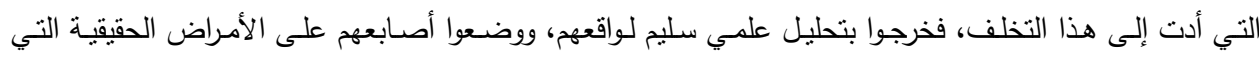

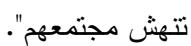
(Muhafah,Ali, 1975) .

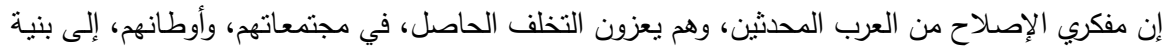

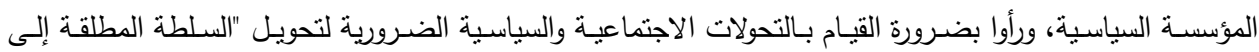

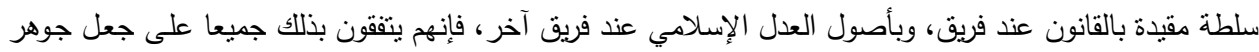

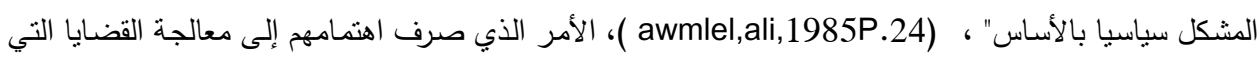
تتصل بالدولة والمجتمع وتنظيمها. لقد كان للتيارات الأوروبية الرائجة آنذاكك أثرها في تكوين آراء تقدمية لائ المفكرين، العرب وبالأخص السوريين منهم، كما يتبين من كتابات محمد كرد علي، وعبد الرحمن الكواكبي، وحقي بك العظم وأديب إسحق وفرح الكران

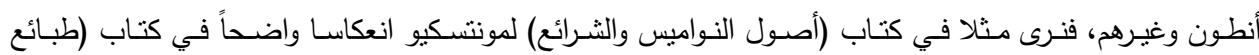

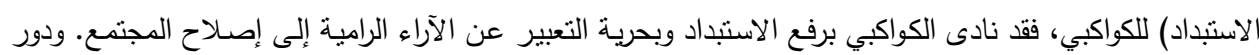

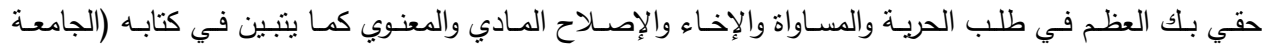

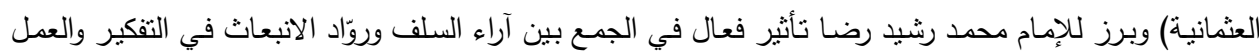

على دعم السيؤولية الذاتية في حركة الإصلاح عامة... (Farah,Caesar,1990)

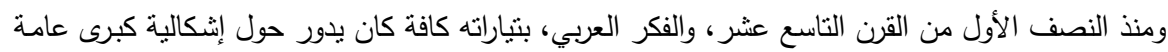

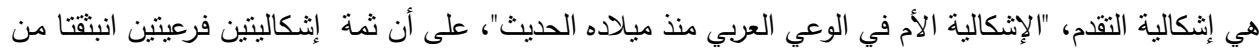

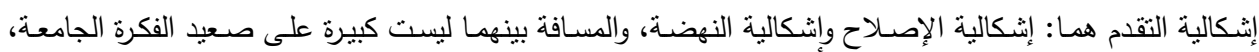

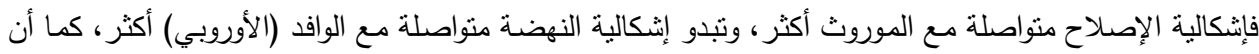

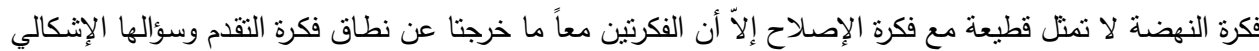

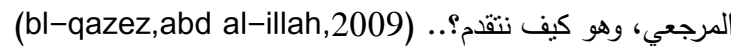

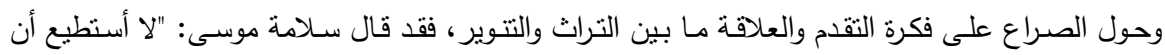

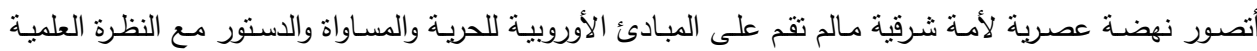

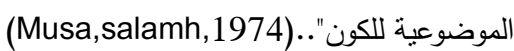
ومن هنا فقد دارت كل الأسئلة لتعبر عن هاجس التقدم وجملة الأسئلة الني يطرحها على الذات: ماذا نأخذ

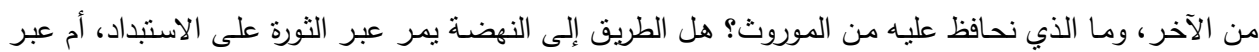


الإصلاح الاجتماعي، أم عبر الإصلاح الديني؟ ما دور الدولة في عملية الإصـلاح، وما دور المتقفين في التتوير .

(bl-qazez,abd al-ilah,2009)

كان واضحاً أن أطروحسة التقدم قد هيمنت على أفكار مفكري تلك الحقبـة الأصـلاحية فقد أصبح، كما

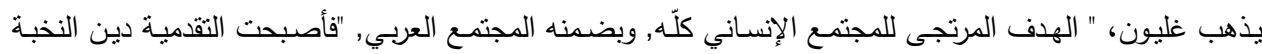

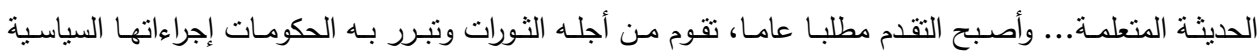

والاقتصادية, وصار مصدر مشروعية الكلام والعمل معا. (Gleoun,Burhan,1985)

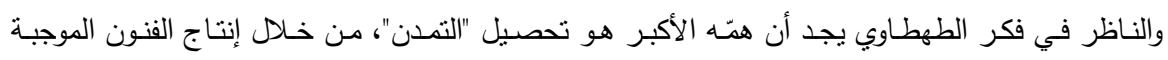

لتقدمه، معنوياً ومادياً، وذللك بترقية الآداب والفنون وبالتقدم في المنافع العمومية - المادية - التي تدور على العمل

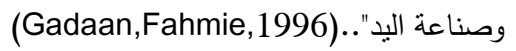

وبالمنل جاء خير الدين التونسي، و"استكمل, في مشروعة التمدني، منظومة الحداثة الغربية بأن أضاف إلى إلى

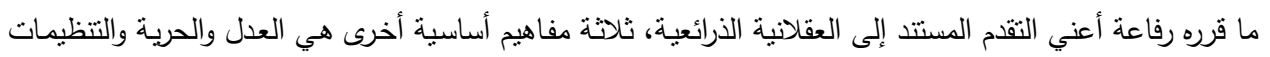
الدنيوية الإدارية، وهي مفاهيم جوهرية في مركب الحداثة".

ويجد رضوان ال(Gadaan,Fahmie,1996) سيد أن مفهوم التقدم، عند خير الدين التونسي، وبالمثل مهئل

عند الجمهور الأكبر من مثقفي الفكر النهضوي جاء لكي يقرر أمرين حاسمين وهما: أن التمدن هو المسألة التي

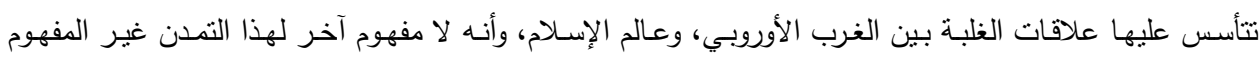
الأوروبي.. (al-saed,Rudwan,1998)

من هنا فإن الطريق الناجع أمام البلاد العربية الإسلامية لتعزيز قوتها، وإنجاز تقدمها، هو أن تسعى إلى اقتباس هذا التمدن.

لقد انطلق كل من الأفغاني ومحمد عبده من فكرة الإصلاح الديني، أما الطهطاوي وخير الدين التونسي، فقد

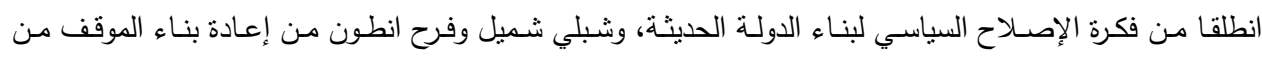
الطبيعة على أسـاس علمي. (Hanafi,Hasan,2001)وهذه المنطلقات جميعها يمكنها بنظر هؤلاء تحقيق التقدم

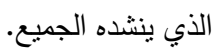

لكن عبد الإله بلقزيز يرى أن معنى التقدم، ومعنى الحداثة في الفكر النهضوي العربي توزع بين مفهومين، وبالتالي، بين خيارين. فقد عنى، عند بعضهه، نقد القديم بما هو نظام يملك سلطانا على الأفكار والقيم والعلاقات.

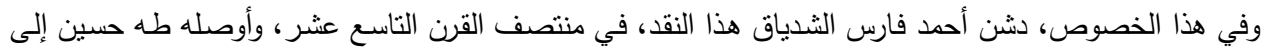
ذروته في منتصف القرن العشرين، كما أنه عنى، عند بعض، استلهام النموذج الأوروبي، والتبشير بـه، فقد فعل ذلك بتفاوت شبلي شميل وأنطون سعادة وأحمد لطفي السبد وسلامة موسى وعباس العقاد، وقد يحدث أن يتجاوز المعنيان

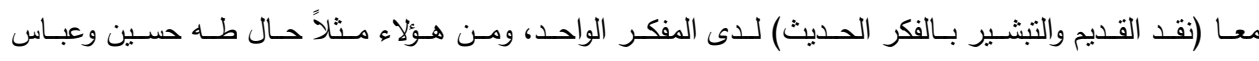

(Blkazez,Abd al-elaah,2007)... العقاد

هكذا يتبين أن الأسـاس الفكري عند التتويريين العرب يتمحور حول فكرة التقدم، ونقد الاستبداد، وطلب الحضارة، وهو ما كان يميز الجانب الدنيوي من الفكر الإسلامي في القرن التاسع عثر •

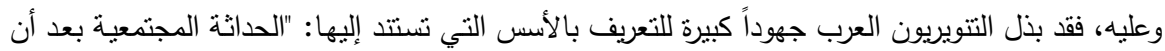
حدوها في: الحرية، والعدل، والمساواة, والمواطنة، والعلم، وحب العمل. وجاءت الحرية في صدارة هذه الأسس-al) shareef,maheer,2000) 
من هنا برزت مسألة حقوق الإنسان في فكر النهضة في إطار المجال السياسي الذي كان يشغل مفكري

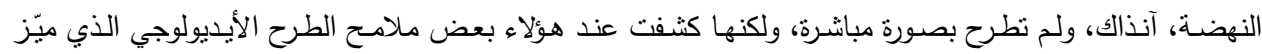

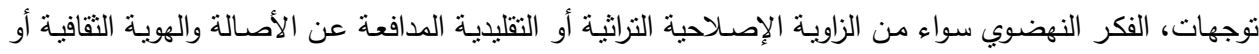

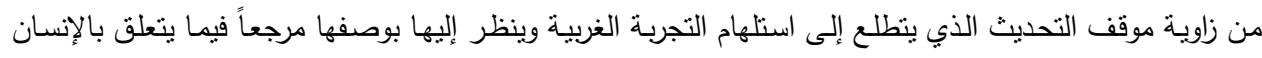

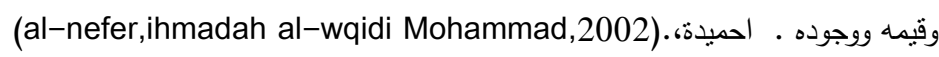

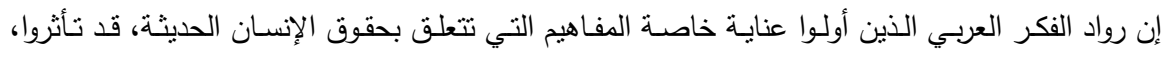

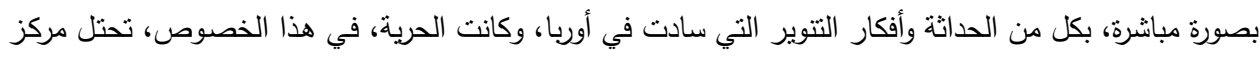
الاهتمام الرئيس لرواد الفكر العربي • (al-madinie,tawfiq,2002.

وييدو أن ما ميّز هذه المفاهيم هو أنها فصلت بين نسقين مهمين للفكر ـ ويلخص كمال عمران أوجه التباين

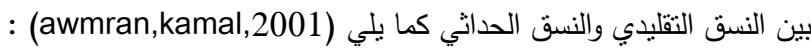
للنسق النقليدي مرجعية غيبية ودينية، وللنسق الحداثي مرجعية إنسوية دنيوية.

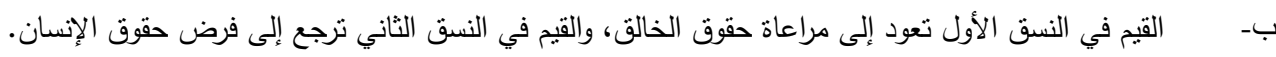

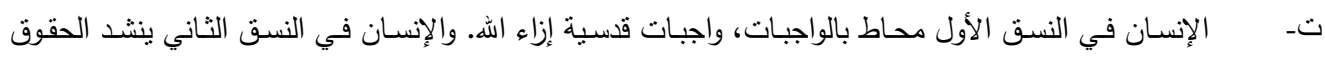
الفردية كحرية التعبير والاختيار في ظل الحقوق السياسية الناشئة عن النظم والمؤسسات.

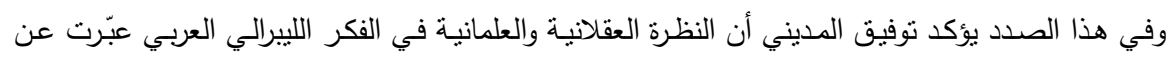

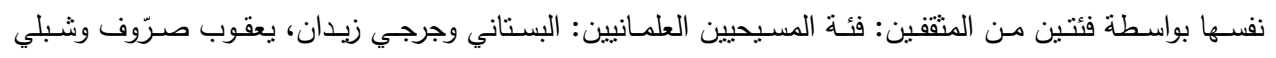

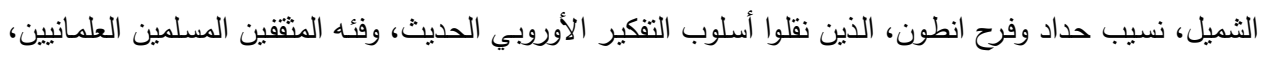
التي كان من أبرز منظريها قاسم أمين، ولطفي السيد. (Akmadanie,Tawfiq,2002)

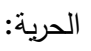
شهدت البلاد العربية، في القرن الثامن عثر ، تحولات هامة تحت ضغط الغرب، وفي مواجهته، وكانت أبرز

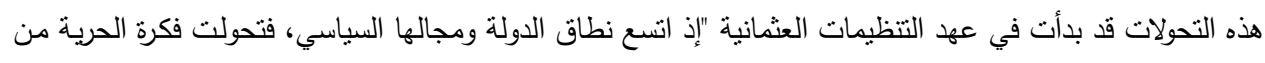

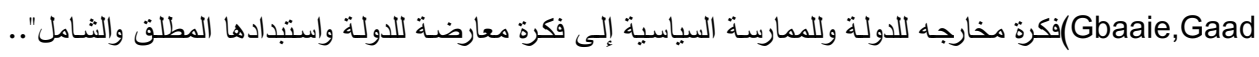
al-kareem,2003)

وسرعان ما اندلعت الثورات في البلاد العربية تطالب الدولة العثمانية بالحرية والاستقلال، وتدعو إلى حق الإنسان

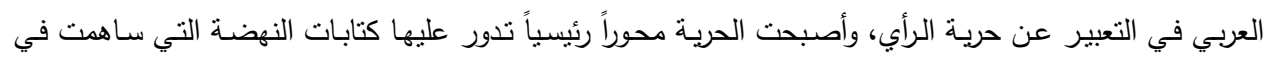

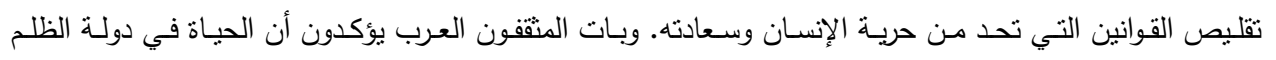

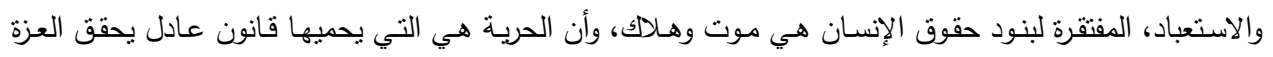
والكرامة. (maliqie,munther,1986)

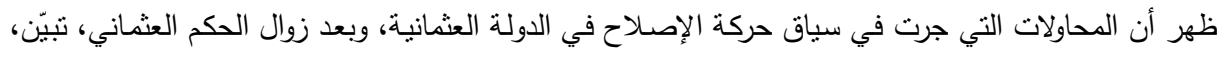

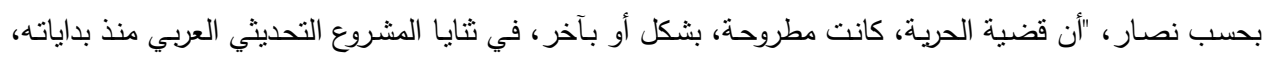

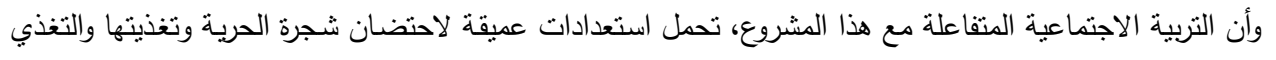

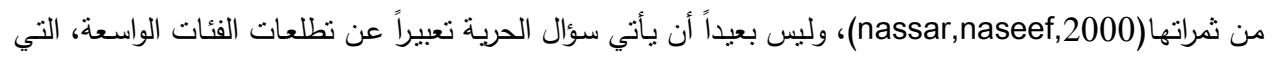

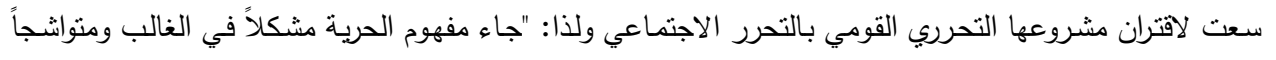

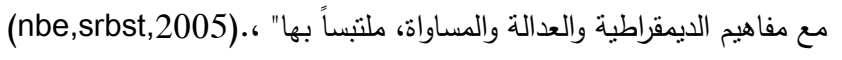


ففي كثير من الأحيان ظهرت فكرة الحريـة، في العالم العربي، وبالأخص لدى المثققين العرب، ليس

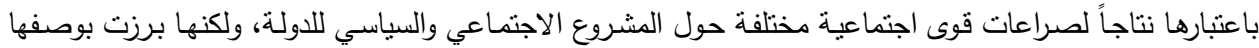

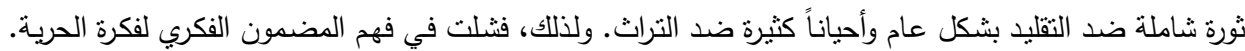

(Gleoun,burhaan,1985)

وفي هذا الخصوص يرى علي محافظة أن المفكرين العرب قد دعوا إلى "الحرية بمفهومها الثشامل الواسع،

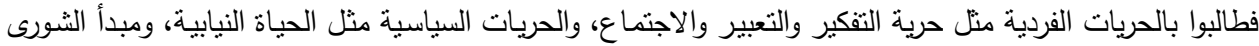

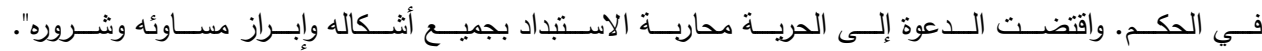

(Muhafadah,ali,1975)

ويُيرز ناصيف نصار أن سؤال الحرية الذي طرحته النهضة العربية الأولى، كان سؤالاً مركزياً، وقد أكد

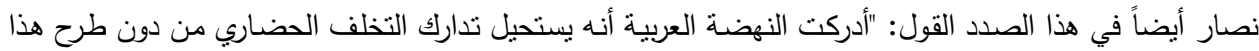

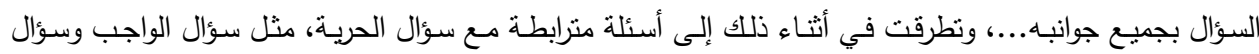

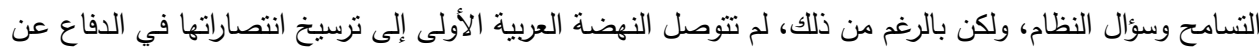

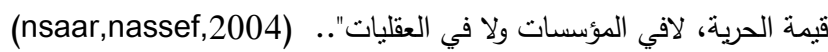

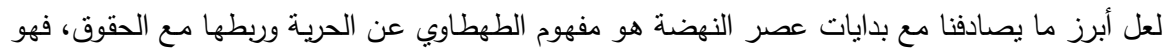

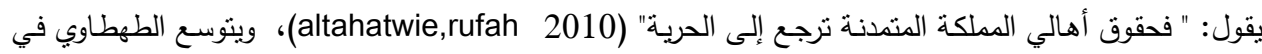

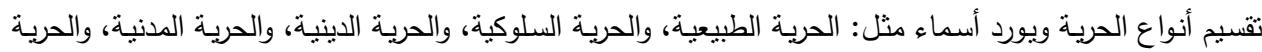
السياسية، ويشرح مفهوم كل نوع من هذه الحريات التي تدور حول الفرد ومقولة الإنسان، ويعرَّف الحرية السياسية الكردية بأنها " تأمين الدولة لكل أحد من أهاليها على أملاكه الثرعية المرعية وإجراء حريته الطبيعية بدون أن تتعدى عليه

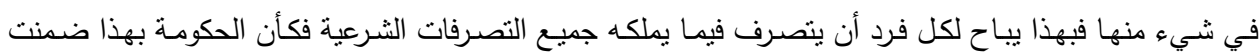
للإنسان أن بسعد فيها مادام مجتنباً لأضرار أخوانه".(nassar,naseef,2004)

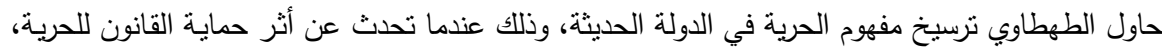
يقول: "ثم إن أخوة العبودية الني هي التساوي في الإنسانية عامة في حقوق أهل المملكة بعضهم على بعض الته التي

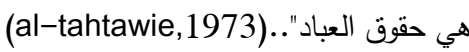
وأضاف الطهطاوي إلى هذا التعريف حرية العقيدة الدينية، أي حرية المذهب والمعتقد، معتبراً إياها عماد الوحدة الوطنية وحذر من عاقبة التثخل في الحرية الدينية ، (altahtawie,1973) كما يييّن الطهطاوي أن العدالة القانونية تهدف إلى رفع الظلم بين الناس في سائر الحقوق، وذللك: "لتعرف التهان

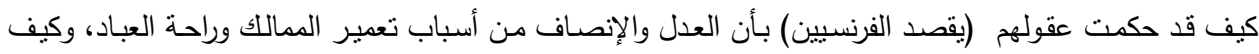

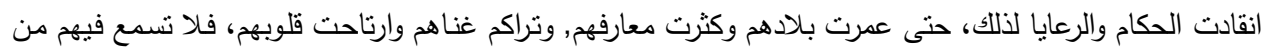
بثكو ظلماً أبدا، والعدل أساس العمران".. (al-tahtawie,B.t)

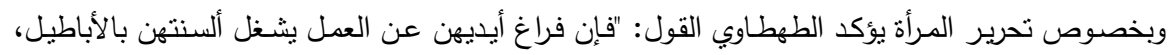

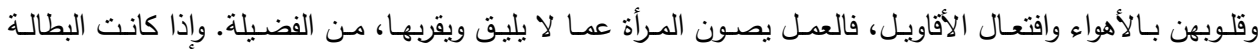

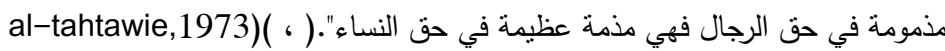

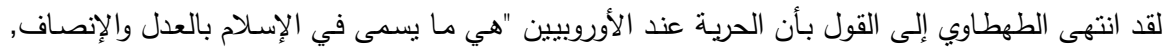

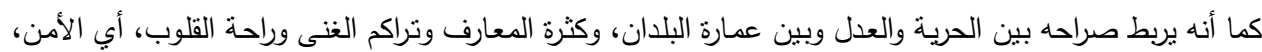

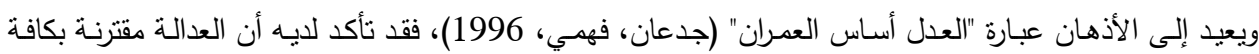


أثنـكال - الحريـة-: الحريـة المدنيـة أو حقوق النـاس، والحريـة السياسـية، والحريـة الطبيعيـة والحريـة الدينيـة، والحريـة السلوكية- وهي حريات ينبغي أن تكفلها على دولة القوانين، "وبذللك يصبح ثالوث النهضة عند الطهطاوي، قائما على تلى الحرية والمساواة والعدل. Gdaan,Fahmie,1996)

ويُلاحظ أن الحريـة السياسية عند الطهطاوي، قد عُرفت بالأحكام القانونية التي تصون أمن الدولة وتحمي

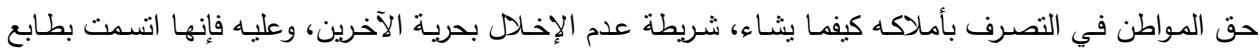
سياسي، واستأثرت بالحياة النيابية الدستورية، وحكمها الديمقراطي الذي جعل المواطنين رقباء على القوانين الإدارية والنتريعات السياسية،.(al-maaliqe,munther,1986)

يرى خير الدين التونسي، كمـا الطهطاوي، أن الحريـة والمسـاواة عند أهل أوروبـا مرادفتان عند المسلمين

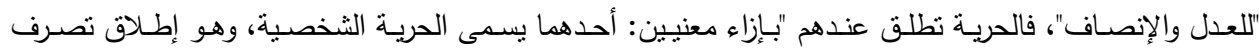
الإنسان في ذاته وكسبه مع أمنه على نفسه وعرضـه وماله ومساواته لأبناء جنسه لدى الحكم.... [أما المعنى] الثاني

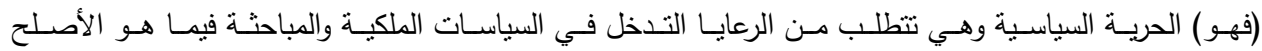
للمملكة. (Al-tunisie,khar al-deen,1978) كمـا أنـه يؤكد فكرتي العدل والحريـة بوصفهما "دعامتان ضـروريتين "للعمران في حين (أن الظلم مؤذن

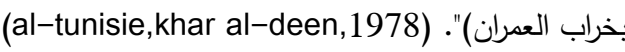
ويزيد مؤكداً فكرة ازدهار العمران بسبب وثيق من هاتين الدعامتين، "فإذا كان العدل والحرية سببي الازدهار

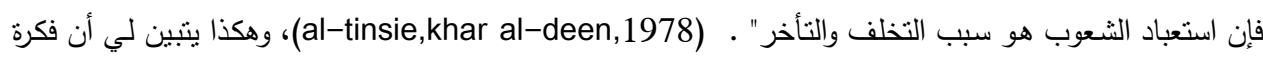
الحرية مثلت نقطة التقاء وانطلاق عند مفكري عصر النهضة. من جهنه جاء الأفغاني مُُهداً لتيار فكري قطع صعوده التيار العلماني الذي استلهم الفكر الليبرالي الغربي عامـة، وأفكار الثورة الفرنسية خاصـة، وتتلمذ على الأفغاني محمد عبده الذي أصبح محور جيل كامل من الأدباء أمثال: محمد حسين هيكل، وطه حسين، وأحمد أمين وغيرهم. (Almusale,Ahmad,2001)

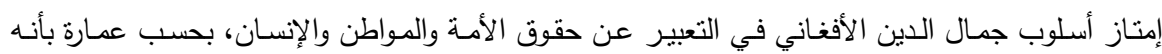
تحريضي ونضالي. ومحور التحريض، عنده هو التركيز على تعيين مساوئ الحكم الفردي، المطلق، وإبراز حسنات

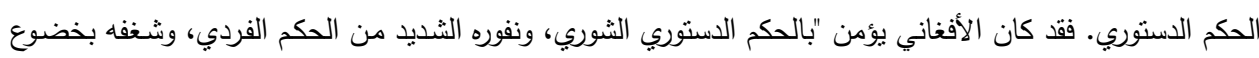
الحاكم للقانون الذي يضعه الشعب ملائما لاحتياجاته ومراحل تطوره". (al-afaganie, without date)

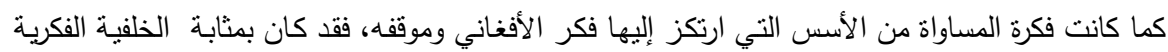

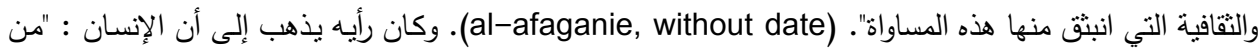
أكبر أسرار هذا الكون، ولسوف يستجلي بعقله ما غمض وخفي من أسرار الطبيعة..." ". ( al-afaganie, without (date أمّا الإمام محمد عبده فقد انطلق تفكيره، كما الأفغاني، من قضية، "الانحطاط الداخلي، والحاجة إلى البعث

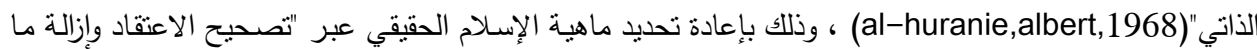

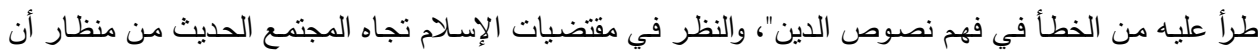

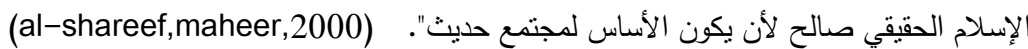
كانت إحدى غايات محمد عبده الرئيسة تتمثل في أن يُظهر إمكان التوفيق بين الإسلام وبين الفكر الحديث؛ مؤكداً أهمية العقل للوصول إلى المعرفة الدينية، كما كان يرى أن المجتمع الأمثل هوالذي يذعن لأوامر الله، ويؤولها لإنها 
تأويلا عقليـا في ضـوء المصـلحة العامـة، على اعتبـار أن أوامـر الله هي أيضـا مبـادئ المجتمع البشـري.-al) bert,huranie,1968)

وقد اهتم محمد عبده بالإنسان الحر ووضعه في مركز تفكيره. يقول: "لا وطن إلا مع الحرية، بل هما سيان،

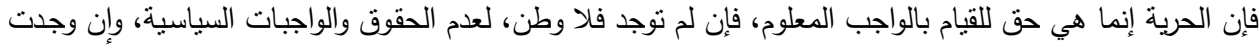

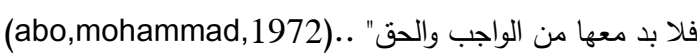
أمسا الكواكبي، فقد وجهه نقداً لاذعـاً للحكم الاستبدادي المعادي للحريات، فكان من أكبر دعاه المبادئ

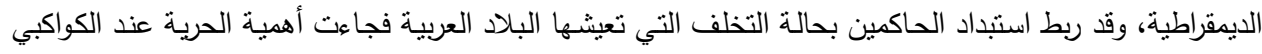

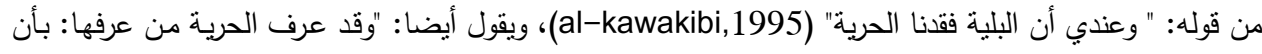

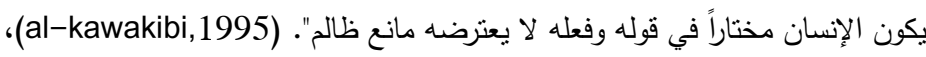

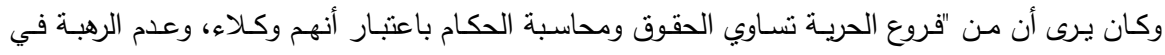

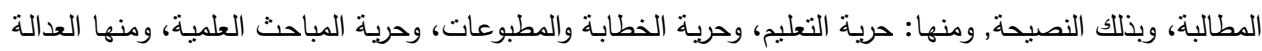

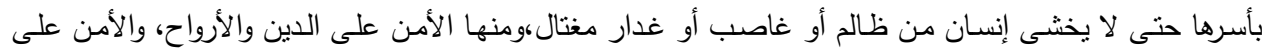

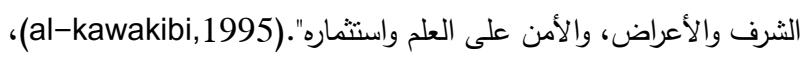
وحول نظرته إلى الاستبداد، فهو نظر إلى المستبد وسلوكه بأنه: " يتخذ المتهجدين سماسرة لتعزيز الأمسة

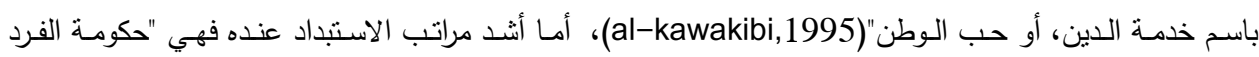
المطلق(al-kawakibi,1995)،

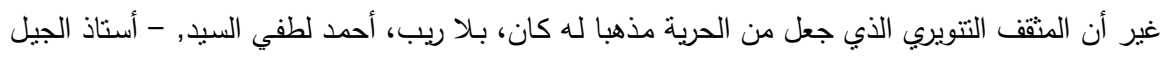

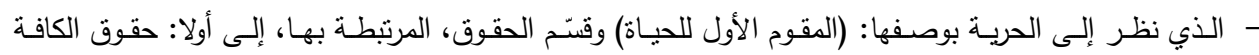

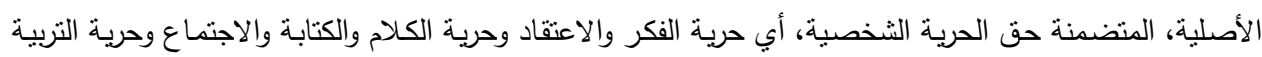

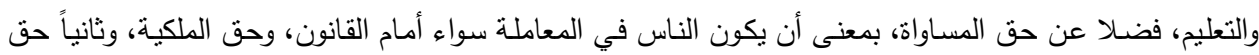
الأمة في حكم نفسها بنفسها.. (Alshareef,Maher,2000) أطلق لطفي السيد على مذهبه اسم مذهب الحريّين: (وهو اصطلاح أخذه عن الطهطاوي، ويعني في اللغة

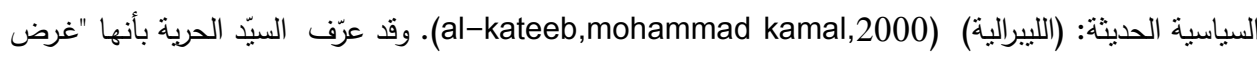
الإنسان في الحياة، كانت ولا تزال هواه الذي طالما قدم له القرابين، وانفق في سبيله أعز شيء عليه. أنفق في سبيله بانه

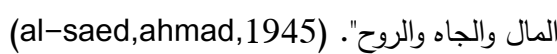
al- ويضيف، بخصوص أصالة فكرة الحرية"، وما لزوم الحرية للإنسان باقل من لزوم الأرواح للأبدان".

(saed,ahmad,1945

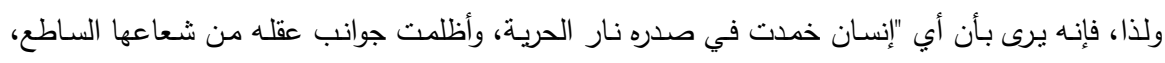
جدير بأن لا يعثبر إنساناً وأن تسقط عنه تكاليف الحياة". (al-saed,ahmad,1945).

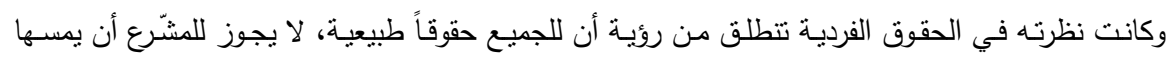

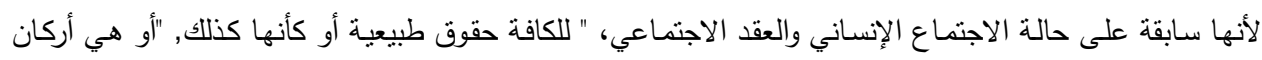

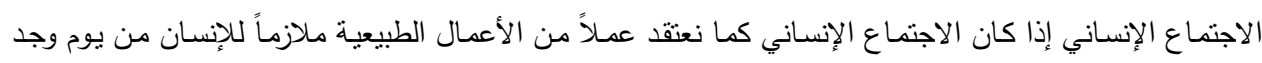

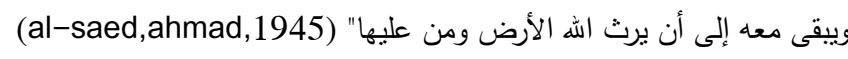

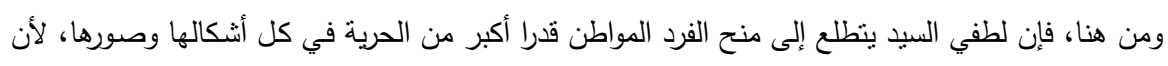

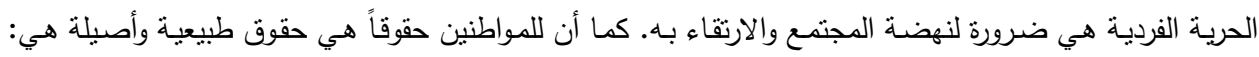


حق الحرية الثخصية بمعناها العام وحرية الفكر والاعتقاد والكتابة وحرية التربية والتعليم في حدود لا تضر بالغير . ((al-saed,ahmad,1945

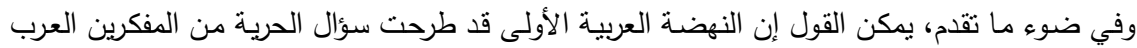

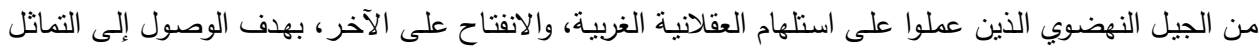

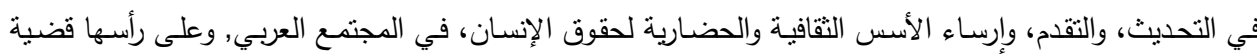

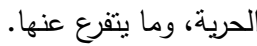

وبيرز عزت قرني أن الحرية عند الدفكرين النهضويين لم تكن تتحصر في حقولها العملية، لا سيما في ميدان

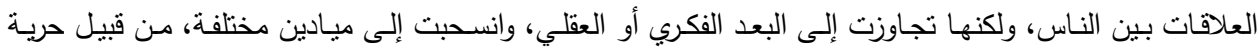

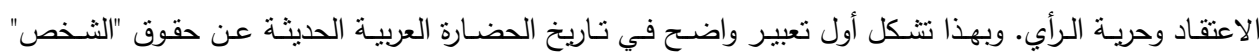
الإنساني من حيث هو كائن مستقل بذاته.. (al-qarnie,izaat,1980)

لقد ذهب بعض رواد النهضـة من المفكرين المسلمين إلى تأكيد حرية التعبير، والاعتقاد، وحق اختيار

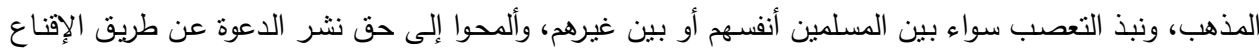

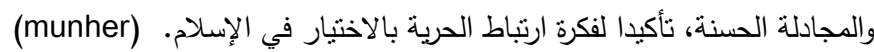

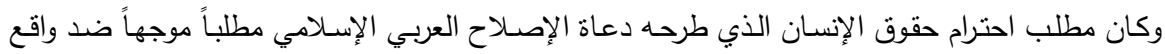

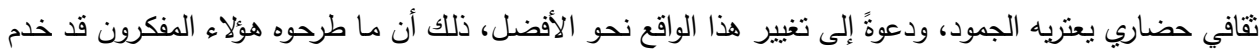

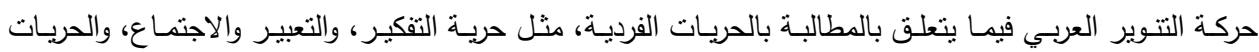

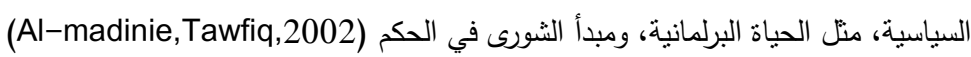

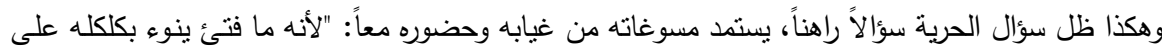

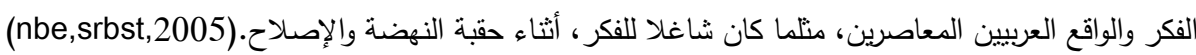

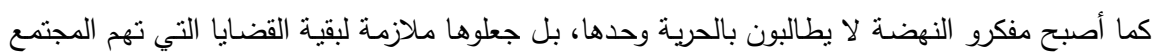
والإنسان، على أساس تحقيق المصالح والمنافع التي ينبغي أن يوفرها الوطن للفرد.

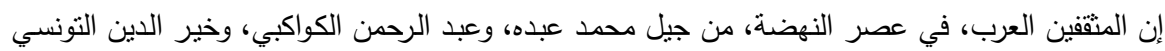

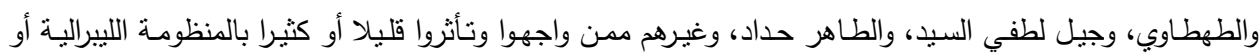
بعض مفاهيمها، يتميزون بحسب ابراهيم أعراب بخاصيتين (aarab,ibraheem,1997):

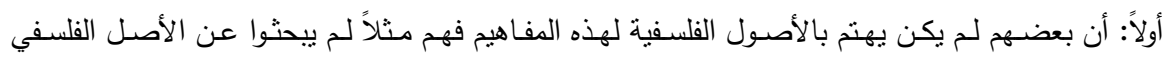

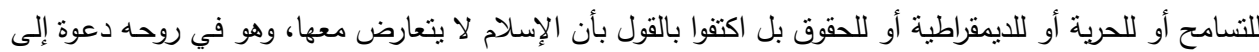

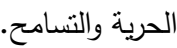
ثانيا: سعيهم الدائب إلى الثأصيل، أي تأصيل تلك الدفاهيم داخل المرجعية التراثية والثقافية الإسلامية، مما

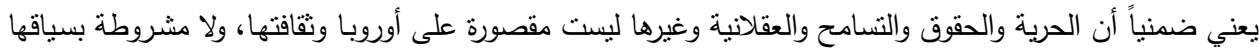

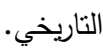


References:

1. Almadine, Tawfiq, (2002), "pluralism at the culture Arabic And rights Human," within Book: (Human Human at Thought Arab), (edit) Salma Jayyousi, (i 1), Beirut: Center studies Unit Arabic, P. 833.

2. Blrashed, Mohammed, (2009), Enlightenment European: Think the movement Correctional The world Arabi, magazine Writings Contemporary, Volume 71 Issue 18 December II / February, Beirut, p . 100.

3. A reference the previous, P. 101.

4. Gaad, Hisham, (1986), Effect philosophy Enlightenment On has evolved Thought at the world Arabi Islamic, magazine Thought Arabi Contemporary, Issue 37 December the first, Canon Second, Beirut: Center Development National, p . 20.

5. Khatib, Mohammed Full, (2001), formation Renaissance Arabic, 1800- 2000, Damascus: Press Yazigi, P. 97.

6. C Bai, Gad Karim, (2003), op . Cit ., P . 27.

7. The world, Mahmood Amin, (1989), reference former, P. 181.

8. Gbaie, Hisham, (1986), reference Earlier, p. 25.

9. Nsar, Nassif, (2004), reference former, P . 324.

10. Amran, Kamal, (2001), reference former , P . 309.

11. Khaddour, Jamal, (2002), (et al. ) Issues Renaissance Enlightenment, Oman: Ministry Culture, p. 169.

12. A Moussalli, Ahmed, (2001), reference former, P. 126.

13. G. Lyon, Burhan, (1998), (dialogue) Ahmed past, The Arabs And challenges

Century the one Twenty, (i 1), Amman / Jordan: forum Slave Hamid Shoman

Cultural activities , P . 15.

14. Balqiz, Abd al-Ilah, (2009), op. Cit., P. 41.

15. Nassar, Nassif, (2004), Thinking and Migration from Heritage to the Second Arab

Revival, op. Cit., P. 319.

16. Nassar, Nassif, (2000), the second Arab renaissance and the challenge of Freedom, reference former, P. 149.

17. Salim, Nabil, (89/1990), Respect for Human Rights and National Commitment, Journal of Unity, No. 63/64, Sixth Year, December, Rabat, p36.

18. Nuehid , Bayan , (2002), "Human Rights in the historical modern Arabic texts", within the book: (Human Rights in the Arab Thought), .. 7 reference former 51.

19. Salamh, Yousef, (2002), the problem of freedom and human rights in modern Islamic Arab Thought "in the book: (Human Rights in the Arab Thought), op . reference former 662.

20. Al_Ansari, Mohammed Jaber, (2000), the composition of the political significance of the Arab and Qatari state, (i 3), Beirut: Center for Arab Unity Studies, p . 55.

21. Nassar, Nassif, (2004), thinking about immigration, op . reference former. 322.

22. Shrabi., Hisham, (1978 ), Arab and Western Intellectuals, (I 2), Beirut: Dar al-

Nahar, p. 85.

23. G. Leon, Burhan, (1981), Politics and Ethics, the Arab Thought Magazine, Issue 22 September October (October) the third year, Beirut, p150-151.

24. A Moussalli, Ahmed, (2001), reference former, P . 125.

25. Blkuziez, Abdul Ilah, (2009), from the Renaissance to modernism, p . 47 (margin).

26. A previous reference, p. 12.

27. G. Leon, Burhan, (1987), the question of democracy and international Alastratejbh, Journal of Contemporary Arab Thought, No. (47) Fall, Beirut, the National Development Center, p. 103. 
28. Abd Al_latef, Kamal, (1997), Arabs, modernity and politics, (i 1), Beirut: Dar Vanguard Printing and Publishing, p . 17.

29. Abd Al_latef, Kamal, (2002), "Human Rights in the Arab World", reference former.p 53 .

30. G. Leon, Burhan, (2002), "Human Rights in the Arab contemporary political thought", a book :( Human Rights in the Arab Thought), reference former, P . 383.

31. Rabeh, Mohamed Abdelaziz, (B.t), the other face of the defeat of the Arab, London: Riad Al Rais books and publishing, p . 187.

32. Blk uziez, Abdul Ilah, (2009), from the Renaissance to modernism, op . reference former. 35 .

33. Al_sharef,Maher, (2007), " the causes of relapse Project Renaissance and the Enlightenment and the terms of mobilization of Arab reality again, " in the book: (Arab Alntam Crisis and Problems of Renaissance), (i 1), the Arab spread Foundation, p . 79.

34. Ggaan , Fahmi, (1979), the foundations of progress on the thinkers of Islam, (i 1), Beirut: Arab Foundation for Studies and Publishing, p . 322.

35. A Sharif, Maher, (2007), op . Cit ., P . 80.

36. G. Leon, Burhan, (1990), the sectarian system: from the state to the tribe, Beirut:

Arab Cultural Center, p . 137.

37. Nade, Serbest, (2005), reference former., P . 27.

38. A Min, Samir, (1991), some of the future issues, (i 1), Cairo: Madbouly Library, p . 53.

39. Khatib, Mohammed Kamel, ( 2001), ibid., P. 103.

40. A Tepe, Bassam, (2002), "economic and social reconstruction of democracy", in a book: ( The Crisis of Democracy in the Arab world), (i 3), Beirut: Center for Arab Unity Studies, p. 85.

41. Gdaan, Fahmi, (1979), reference former., P . 327 (margin).

42. Hanfi ,Hassan, (2001), reference former. , P . 79.

43. C whisperings, Fahmi, (1979), reference former. , P . 327 (margin).

44. A Dajani, Ahmed Sidqi, (2002), " the evolution of the concepts of democracy in the modern Arab thought", within the book: ( The Crisis of Democracy in the Arab world), op . reference former. 132-133.

45. A Moussalli, Ahmed, (2001), reference former., P . 133.

46. Abd Al-fatah , Nabil, (2000), "State of independence in the face of civil society", within the book : (renewal of political thought in the framework of democracy and human rights), p. 122.

47. Khatib, Mohammed Kamel, (2000), the composition of the Arab Renaissance 1800, op . Cit . , P . 103.

48. G. Leon, Burhan, (2007 ), "Crisis of the Arab Systems Inclusive", in the book: (the crisis of the Arab system and the problems of the Renaissance), p40 .

49. A Tepe, Bassam, (2002), "economic and social reconstruction of democracy", in a book: ( The Crisis of Democracy in the Arab world), op . reference former. 86.

50. A Laroui, Abdullah, (1973), Arab and historical thought, Beirut: Dar truth, p . 15.

51. Saaed, Mohammed Al-saed, (1997), towards establishing the legitimacy of human rights in the Arab culture, magazine doors, No. (14), Beirut: Dar Al - Saqi, p . 10.

52. Al-aleem, Mahmoud Amin, (1989), the Arab Thought between privacy and cosmic, Cairo: Dar Arab Future, p . 181.

53. Trabaishe, George, (1982), the Qatari state and national theory, (i 1), Beirut: Dar Vanguard, p . 22.

54. Al-rzaz, Munif, (1965), freedom and its problem in underdeveloped countries, Beirut: Dar Ilm, p . 37. 
55. A previous reference, p. 37.

56. A previous reference, p. 38 .

57. Hurani, birrat, (1968), . reference former. 411.

58. Al-rzaz, Munif, (1965 ), Freedom and its Problem in Underdeveloped Countries, op. Cit., P. 40.

59. A previous reference, p . 111.

60. Al-rzaz, Munif, (1985), The Complete Works, Part I, (i 1), Dar average, p . 71.

61. The Hanandeh, Maher Mahmoud Shteiwi, (1996), the concept of freedom in thought Munif Razzaz, Master Thesis, supervision: A. Hamad Al Madi, University of Jordan, p . 64.

62. H. Lal, Ali Eddin, (2002), " the concepts of democracy in modern political thought" in a book ( The Crisis of Democracy in the Arab world), p . 48.

63. The Najafi, Salem, (2008), "contemporary nation - state crisis", within the book: (contemporary national state and the crisis of integration and dismantling), Beirut: Center for Arab Unity Studies, p. 12-13.

64. Hourani, Albert, (1968), op. Cit., P. 411.

65. Trabaishe, George, (1982), the Qatari state and the theory of nationalism, Beirut:

Dar Vanguard, p . 196 (Conclusion).

66. H. Lal, Ali Eddin, (2002), " the concepts of democracy in modern political thought", reference former. , P. 49.

67. A Najafi, Salem, (2008), " the crisis of contemporary nation - state", op . Cit ., P .

15.

68. Nabe, Sarbst, (2005), op. Cit., P. 23.

69. A previous reference, p. 25.

70. G. Leon, Burhan, (2003 ), Arabs and the Transformations of the World, op. Cit., P. 192.

71. Trabaishe, George, (1982), op . Cit ., P . 20.

72. A Dajani, Ahmed Sidqi, (2002), " the evolution of the concepts of democracy in the modern Arab Thought", reference former. , P . 140.

73. Al-Badoor, Salman, (2010/2011), Third World Identity and Civilization, (I 1), Amman: Dar Majdalawi, p. 87.

74. The Kilani, Shams al- Din, (2002), "concepts of human rights in the Islamic sects", within the book: (Human Rights in contemporary Western thought), reference former, $\mathrm{P}$ . 309 .

75. G. Leon, Burhan, (2002), "Human rights in the contemporary Arab political thought", reference former., P . 202.

76. Awmalil, Ali, (1985), reference former, P . 15.

77. The Marzouki, Ibrahim, (1997), HUMAN RIGHTS in Islam, (translation) Mohamed Morsi, (Review) Advisor Hassan Al-Hafnawi, (i 1),, Abu Dhabi / United Arab Emirates: Publications of the Cultural Foundation,P. 442, 535.

78. The Holy Qur'an, Al - Isra, (verse 7).

79. Ammarh, Mohammed, (1985), Islam and human rights imperatives .. not a series of knowledge world, Kuwait 's rights: the National Council for Culture, Arts and Letters, p . 14.

80. The Marzouki, Ibrahim, (1997), the previous reference, p . 535 (margin).

81. Al-bdour , Salman (2010/2011), the third identity and world civilization, op . reference former. 14 . 